\title{
The association of HIF-I $\alpha$ expression with clinicopathological significance in prostate cancer: a meta-analysis
}

This article was published in the following Dove Press journal:

Cancer Management and Research

\author{
Meng Huang ${ }^{1,2}$ \\ Hexi $\mathrm{Du}^{3}$ \\ Li Zhang ${ }^{3}$ \\ Hong Che 4 \\ Chaozhao Liang ${ }^{3}$
}

'Department of Ultrasound, The First Affiliated Hospital of Anhui Medical University, Hefei, Anhui, China;

2Department of Ultrasound, The East District of First Affiliated Hospital of Anhui Medical University, The People's Hospital of Feidong, Hefei, Anhui, China; ${ }^{3}$ Department of Urology, The First Affiliated Hospital of Anhui Medical University and Institute of Urology, Anhui Medical University, Hefei, Anhui, China; ${ }^{4}$ Department of Cardiology, The First Affiliated Hospital of Anhui Medical University and Institute of Urology, Anhui Medical University, Hefei, Anhui, China

Correspondence: Chaozhao Liang Department of Urology, The First Affiliated Hospital of Anhui Medical University and Institute of Urology, Anhui Medical University, No. 218, Jixi Road,

Hefei 230022, Anhui, China

Tel +8655I 62923861

Fax +86 55I 63633742

Email liang_chaozhao@163.com
Background: Hypoxia-inducible factor- $1 \alpha(\mathrm{HIF}-1 \alpha)$ plays an important role in tumor growth, invasion, and metastasis. The aim of this study was to perform a meta-analysis to explore the association of HIF- $1 \alpha$ expression with clinicopathological significance in patients with prostate cancer (PCa).

Methods: A detailed literature search was made in PubMed, Embase, Cochrane Library, China Biology Medicine disc (CBM), and China National Knowledge Infrastructure (CNKI) up to August 21, 2017. Odds ratios (ORs) with 95\% CIs were calculated to evaluate the strength of the correlations. Analysis of pooled data was performed using Review Manager 5.3 software. Results: Eventually, 14 studies were identified and involved in this meta-analysis. The rate of HIF-1 $\alpha$ protein expression was significantly higher in PCa than in nonmalignant prostate tissues (OR=12.01, 95\% CI: 8.22-17.55, $P<0.00001)$. Similar results were found in different subgroups. There were significant differences between HIF-1 $\alpha$ expression and clinicopathological significance. The expression of HIF- $1 \alpha$ protein was significantly associated with Gleason score (Gleason $\geq 7$ vs Gleason $<7$ : OR=3.58, 95\% CI: $2.35-5.46, P<0.00001$ ). The frequency of HIF-1 $\alpha$ protein expression was significantly higher in T3-T4 stages than in T1-T2 stages of PCa $(\mathrm{OR}=3.70,95 \% \mathrm{CI}: 1.53-8.96, P=0.004)$. The expression of HIF-1 $\alpha$ protein was significantly associated with the presence of lymph node and/or bone metastasis of $\mathrm{PCa}$ (metastasis positive vs negative: $\mathrm{OR}=7.07,95 \% \mathrm{CI}$ : $4.08-12.25, P<0.00001)$.

Conclusion: Taken together, our findings have demonstrated the certain associations of HIF-1 $\alpha$ expression with an increased risk and clinicopathological significance in PCa patients, indicating that HIF-1 $\alpha$ may serve as a valuable biomarker for diagnosing PCa and monitoring the progression.

Keywords: HIF-1 $\alpha$, prostate cancer, clinicopathological significance, meta-analysis

\section{Introduction}

Prostate cancer (PCa) seriously threatens psychological and physical health worldwide. It remains the most common malignancy diagnosed and the third highest cause of leading cancer-related death in males in the USA. An estimation of 2017 cancer statistics revealed 161,360 new cases and 26,730 newly related deaths assigned to PCa. ${ }^{1}$ Currently, although there are different treatment options for PCa including surgery, local radiotherapy, castration, and chemotherapy, the molecular mechanisms for the emergence and progression of PCa remain research focus in recent years. ${ }^{2,3}$ Especially, molecular biomarkers that predict the progression and clinical outcome would allow 
earlier and more appropriate therapeutic approaches for $\mathrm{PCa}$. Therefore, new progressive and prognostic indicators for $\mathrm{PCa}$ are urgently required.

Hypoxia is a reduction in the normal concentration of tissue oxygen which occurs in many diseases including cancer. A key effect of hypoxia is the induction of genetic alterations and angiogenic stimulation, leading to a more aggressive cell phenotype and malignant progression. ${ }^{4}$ Hypoxia-inducible factor (HIF) is a DNA-binding transcription factor, which responds to hypoxia. Recent advances have pointed to the critical role of HIF- $1 \alpha$ in cell development, progression, and the metastasis of $\mathrm{PCa} .{ }^{5,6}$ However, the clinical relevance of the expression of HIF-1 $\alpha$ in PCa remains controversial, and the association of HIF-1 $\alpha$ expression with clinicopathological features is inconclusive due to the relatively small sample sizes in the included study. Meta-analysis can obtain a relatively precise and accurate estimation through incorporating all available evidences using statistical software. ${ }^{7}$ Thus, we conducted a meta-analysis to assess the possible correlations between HIF-1 $\alpha$ expression and clinicopathological significance in $\mathrm{PCa}$, hoping to provide evidences for exploring molecular mechanisms and some novel potential biomarkers of $\mathrm{PCa}$.

\section{Methods}

\section{Ethics statement}

No patient's privacy or clinical samples were involved in this study; hence, ethical approval was not required.

\section{Search strategy}

Literature resources including PubMed, Embase, Cochrane Library, CBM, and China National Knowledge Infrastructure (CNKI) were searched for eligible literatures, using the terms ("hypoxia-inducible factor or hypoxia-inducible factor-1 or hypoxia-inducible factor- $1 \alpha$ or hypoxia-inducible factor-1A or HIF or HIF-1 or HIF-1 $\alpha$ OR HIF-1A") and ("prostatic cancer" or "prostate cancer" or "prostatic carcinoma" or "prostate carcinoma" or "PCa"). Last search of current investigation was updated on August 21, 2017. Additionally, the publication language was only limited to English and Chinese. In case of omission, we identified the reference lists of relevant articles and review articles to seek for potentially relevant studies. We did not contact the corresponding authors if the relevant data were unavailable.

\section{Inclusion and exclusion criteria}

Studies which satisfied the following criteria were included in our study: 1) clinical study about the association of
HIF-1 $\alpha$ expression with PCa risk, 2) studies which contained relevant available data, and 3) PCa was histologically confirmed. Studies were excluded if they met the following criteria: 1) the available data about associations were absent, 2) similar or duplicate study (when the same or similar cohort was applied, after careful examination, the most complete information was included), 3) other type of article including review or abstract, and 4) studies involving cells lines or animal models.

\section{Data extraction}

Based on the inclusion and exclusion criteria, we extracted the relevant information from each eligible publication. Any disagreements were resolved by discussion between authors (Meng Huang and Hexi Du) or reviewed by a third author (Hong Che). The data on first author, publication year, study country, ethnicity, age, sample source, test method, control source, the HIF-1 $\alpha$ cutoff value, T stage, Gleason score, TNM stage, lymph node, and/or bone metastasis status were extracted.

\section{Statistical analyses}

We explored the association of HIF-1 $\alpha$ expression with PCa risk by applying Review Manager software (RevMan 5, The Cochrane Collaboration, Oxford, UK). Odds ratios (ORs) with 95\% CIs were calculated for assessing the concrete relationships between HIF-1 $\alpha$ expression and PCa risk. Meanwhile, the heterogeneity has been assessed via chisquare-based $Q$ and $I^{2}$ tests across studies (no heterogeneity $I^{2}<25 \%$, moderate heterogeneity $I^{2}=25 \%-50 \%$, and extreme heterogeneity $\left.I^{2}>50 \%\right) .{ }^{8}$ In case of extreme heterogeneity ( $I^{2}>50 \%$ or $P<0.01$ for $Q$ test), we used random-effects (DerSimonian and Laird method) model..$^{9}$ Otherwise, fixed-effects (Mantel-Haenszel method) model was introduced. ${ }^{10}$ One-way sensitivity analyses that individually removed publications in meta-analysis were conducted to assess the stability of the results. It mainly explored the impact of a specific study upon mixed OR. Funnel plots were performed to evaluate the publication bias. $P$-value $<0.05$ indicated that there was a bias of study. ${ }^{11}$

\section{Results}

\section{Characteristics of eligible studies}

As a result, a total of 14 studies consisting of 1,342 $\mathrm{PCa}$ samples satisfied the eligible studies (Figure 1). ${ }^{12-25}$ Among them, six were written in English and eight were published in Chinese. The principal characteristics of the included studies are summarized in Table 1. Of these studies, four studies were 


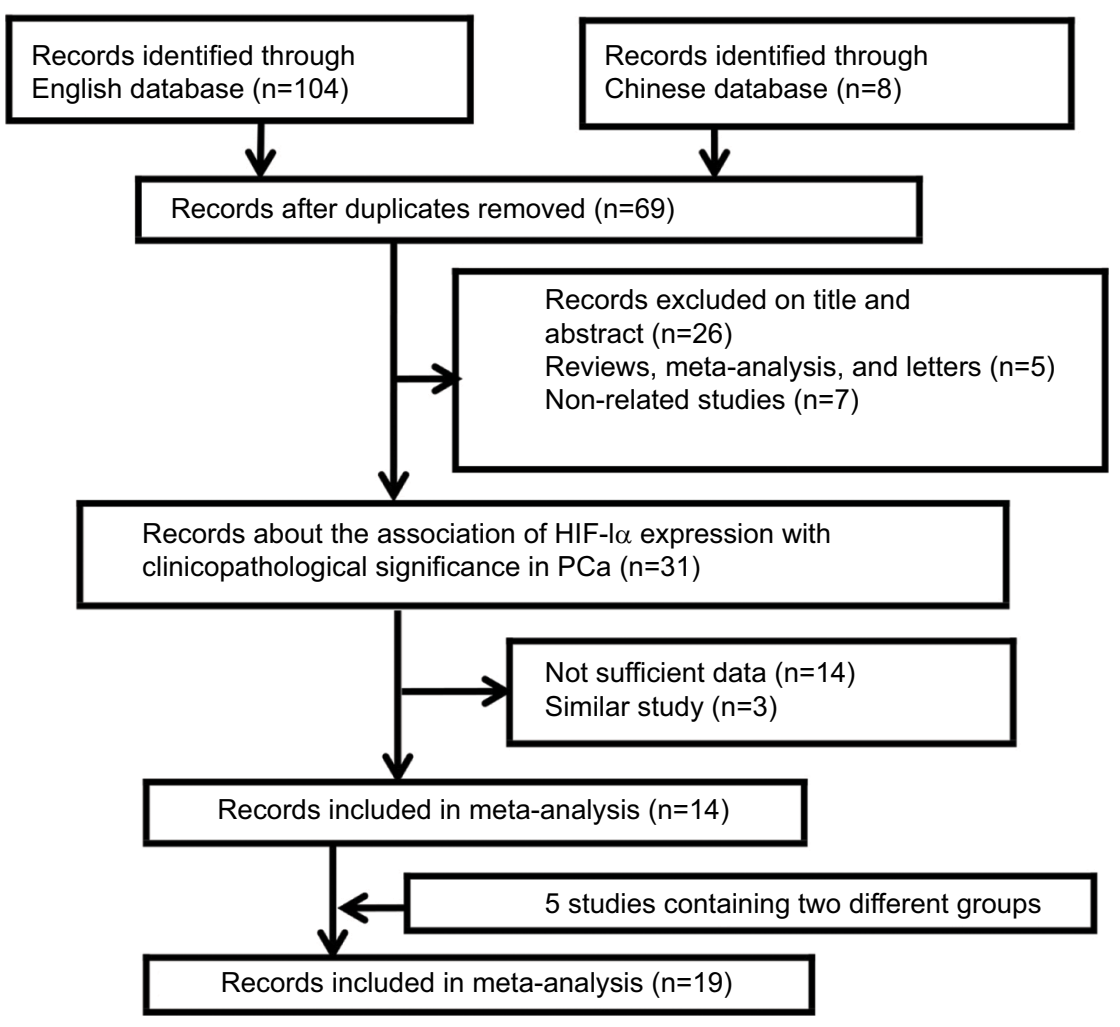

Figure I Flow diagram of the study selection process in the meta-analysis. Abbreviations: HIF-I $\alpha$, hypoxia-inducible factor-I $\alpha$; PCa, prostate cancer.

involved in two control sources that originated from nonmalignant prostate tissues including normal prostate tissue (NP) and benign prostatic hyperplasia (BPH). ${ }^{12,20,23,24}$ One study explored the association of HIF-1 $\alpha$ expression with lymph node and bone metastasis, respectively. ${ }^{18}$ We enrolled these independently into the meta-analysis, and this meta-analysis was eventually established based on 19 studies.

\section{Quantitative synthesis}

Seventeen studies were performed to detect the association between the paired groups. As shown in Figure 2, the rate of HIF- $1 \alpha$ protein expression was significantly higher in $\mathrm{PCa}$ than in nonmalignant prostate tissues $(\mathrm{OR}=12.01,95 \% \mathrm{CI}$ : 8.22-17.55, $P<0.00001)$. Additionally, different subgroups analyses regarding country, ethnicity, sample size, and control source were conducted. A similar result was found in different subgroups (Table 2).

In addition, eight, three, six, and two studies were extracted to explore the association of HIF-1 $\alpha$ expression with Gleason score, $T$ stage, the presence of metastasis, and TNM stage, respectively. Consequently, the association of HIF-1 $\alpha$ expression with clinicopathological significance in PCa was detected. The expression of HIF-1 $\alpha$ protein was significantly associated with Gleason score (Gleason $\geq 7$ vs Gleason <7: OR=3.58, 95\% CI: $2.35-5.46, P<0.00001$ ) (Figure 3). The frequency of HIF-1 $\alpha$ protein expression was significantly higher in T3-T4 stages than in T1-T2 stages of $\mathrm{PCa}(\mathrm{OR}=3.70,95 \% \mathrm{CI}: 1.53-8.96, P=0.004)$ (Figure 4). The expression of HIF-1 $\alpha$ protein was significantly associated with the presence of lymph node and/or bone metastasis of $\mathrm{PCa}$ (metastasis positive vs negative: $\mathrm{OR}=7.07,95 \% \mathrm{CI}: 4.08-12.25, P<0.00001$ ) (Figure 5). The expression of HIF- $1 \alpha$ protein was significantly associated with TNM stage (III+IV vs I+II: OR=6.85, 95\% CI: 2.96-15.87, $P<0.001)$.

\section{Sensitivity analysis}

Each study was deleted one at a time to assess the specific effect of the individual data on the pooled ORs, and oneway sensitivity analyses suggested that pooled results were relatively stable.

\section{Publication bias evaluation}

The funnel plots were largely symmetric (Figure 6), suggesting there were no publication biases in the meta-analysis of HIF-1 $\alpha$ protein expression and clinicopathological features. 
Table I The characteristics of included studies

\begin{tabular}{|c|c|c|c|c|c|c|c|c|c|}
\hline Study & Year & Country & Ethnicity & $\begin{array}{l}\text { Age (years), } \\
\text { median (range) }\end{array}$ & $\begin{array}{l}\text { Sample } \\
\text { size }\end{array}$ & $\begin{array}{l}\text { Test } \\
\text { method }\end{array}$ & $\begin{array}{l}\text { Sample } \\
\text { source }\end{array}$ & $\begin{array}{l}\text { Control } \\
\text { source }\end{array}$ & $\begin{array}{l}\text { Cutoff } \\
\text { value }\end{array}$ \\
\hline Wu et al ${ }^{12}$ & 2016 & China & Asian & - & 14 & $\mathrm{IHC}$ & FFPE & NP/BPH & $>10 \%$ \\
\hline Bao et $\mathrm{al}^{13}$ & 2015 & China & Asian & 71 (59-82) & 100 & $\mathrm{IHC}$ & FFPE & $\mathrm{BPH}$ & $>0 \%$ \\
\hline Guo et $\mathrm{al}^{14}$ & 2014 & China & Asian & $68(47-86)$ & 128 & $\mathrm{IHC}$ & FFPE & $\mathrm{BPH}$ & $\geq 10 \%$ \\
\hline Ranasinghe et $\mathrm{al}^{15}$ & 2013 & Australia & White & 66.6 & 100 & $\mathrm{IHC}$ & FFPE & - & $>0 \%$ \\
\hline Li et al ${ }^{16}$ & 2013 & China & Asian & $67.4(42-79)$ & 124 & $\mathrm{IHC}$ & FFPE & $\mathrm{BPH}$ & $\geq 10 \%$ \\
\hline Huang et $\mathrm{al}^{17}$ & 2012 & China & Asian & $70(45-88)$ & 144 & $\mathrm{IHC}$ & FFPE & NP & $>10 \%$ \\
\hline Li et $\mathrm{al}^{18}$ & 2012 & China & Asian & $65(55-76)$ & 140 & $\mathrm{IHC}$ & FFPE & $\mathrm{BPH}$ & $>0 \%$ \\
\hline Shi et a $\left.\right|^{19}$ & 2007 & China & Asian & $68.7(53-86)$ & 172 & $\mathrm{IHC}$ & FFPE & $\mathrm{BPH}$ & $\geq 1 \%$ \\
\hline Wang et $\mathrm{a}^{20}$ & 2006 & China & Asian & $72(56-86)$ & 64 & $\mathrm{IHC}$ & FFPE & NP/BPH & $\geq 5 \%$ \\
\hline Lekas et $\mathrm{a}^{21}$ & 2006 & Greece & White & 67.8 & 170 & $\mathrm{IHC}$ & FFPE & $\mathrm{BPH}$ & $>0 \%$ \\
\hline Ping et $\mathrm{al}^{22}$ & 2004 & China & Asian & - & 84 & $\mathrm{IHC}$ & FFPE & NP & $>0 \%$ \\
\hline Zhong et $\mathrm{al}^{23}$ & 2004 & USA & White & - & 68 & $\mathrm{IHC}$ & FFPE & NP/BPH & $\geq 5 \%$ \\
\hline Du et $\mathrm{al}^{24}$ & 2003 & Japan & Asian & 65 (57-7I) & 12 & $\mathrm{IHC}$ & FFPE & NP/BPH & $>10 \%$ \\
\hline Zhong et $\mathrm{al}^{25}$ & 1999 & USA & White & - & 22 & $\mathrm{IHC}$ & FFPE & NP & $>1 \%$ \\
\hline
\end{tabular}

Abbreviations: BPH, benign prostatic hyperplasia; FFPE, formalin-fixed and paraffin-embedded; IHC, immunohistochemistry; NP, normal prostate tissue.

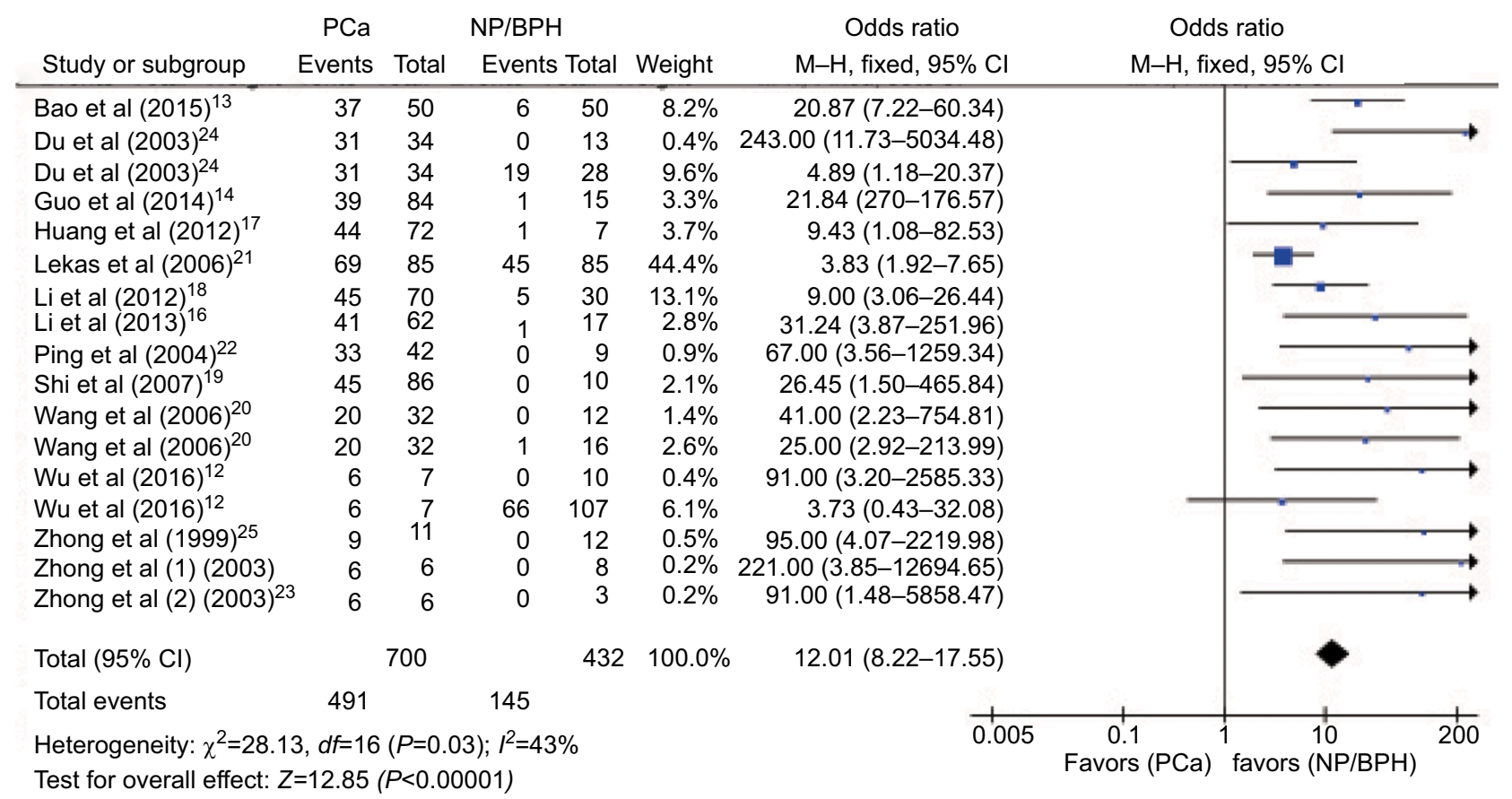

Figure 2 Forest plot for HIF-I $\alpha$ protein expression in PCa and nonmalignant prostate tissue.

Abbreviations: $\mathrm{BPH}$, benign prostatic hyperplasia; HIF-I $\alpha$, hypoxia-inducible factor-I $\alpha$; NP, normal prostate tissue; PCa, prostate cancer.

\section{Discussion}

$\mathrm{PCa}$ is one of the most frequent genitourinary malignancies and has become a pivotal cause of male cancer-related deaths worldwide. Particularly, PCa patients often progress to a castration-resistant disease state after receiving initial hormonal therapy over 2-3 years. ${ }^{26,27}$ Advanced metastatic PCa is accompanied with metastasis to bone, lung, and lymph node. Therefore, the morbidity of PCa has exhibited a sharp increase in recent years. However, the development and progression of $\mathrm{PCa}$ remains poorly understood. Therefore, it is particularly important to explore the underlying mechanisms associated with prostate malignant transformation, which efforts should hold great promise in the clinical therapy for PCa. It will also greatly benefit PCa patients who may be utilized in the prediction of PCa outcome and therapeutic efficacy.

Hypoxia is one of the most common conditions that drives development and progression of a variety of disease including cancer. Approximately $60 \%$ of the solid tumors exhibit less than $1 \% \mathrm{O}_{2}$ concentration in comparison with 
Table 2 Stratified analysis of HIF-I $\alpha$ protein expression in PCa and nonmalignant prostate tissue

\begin{tabular}{|c|c|c|c|c|c|c|}
\hline Categories & Subgroups & $\mathbf{n}$ & OR (95\% Cl) & $P$-value & $I^{2}$ & $P^{h}$ \\
\hline All & & 17 & I2.0| (8.22-I7.55) & 0.000 & 0.431 & 0.030 \\
\hline \multirow[t]{2}{*}{ Country } & China & 11 & $17.58(10.12-30.55)$ & 0.000 & 0.000 & 0.775 \\
\hline & Other & 6 & $22.97(4.82-109.39)$ & 0.000 & 0.680 & 0.008 \\
\hline \multirow[t]{2}{*}{ Ethnicity } & Asian & 13 & 16.89 (10.28-27.75) & 0.000 & 0.024 & 0.422 \\
\hline & White & 4 & 32.41 (2.76-379.86) & 0.006 & 0.678 & 0.030 \\
\hline \multirow[t]{2}{*}{ Sample size } & $\geq 100$ & 7 & $9.13(5.82-14.30)$ & 0.000 & $0.45 I$ & 0.091 \\
\hline & $<100$ & 10 & $22.00(10.31-46.97)$ & 0.000 & 0.321 & 0.151 \\
\hline \multirow[t]{2}{*}{ Control source } & NP & 7 & $49.10(15.99-150.83)$ & 0.000 & 0.000 & 0.653 \\
\hline & $\mathrm{BPH}$ & 10 & $8.98(5.92-13.61)$ & 0.000 & 0.370 & 0.112 \\
\hline
\end{tabular}

Abbreviations: $\mathrm{BPH}$, benign prostatic hyperplasia; HIF-I $\alpha$, hypoxia-inducible factor-I $\alpha$; NP, normal prostate tissue; OR, odds ratio; PCa, prostate cancer; $P^{\text {h }}, P$-value of heterogeneity test.

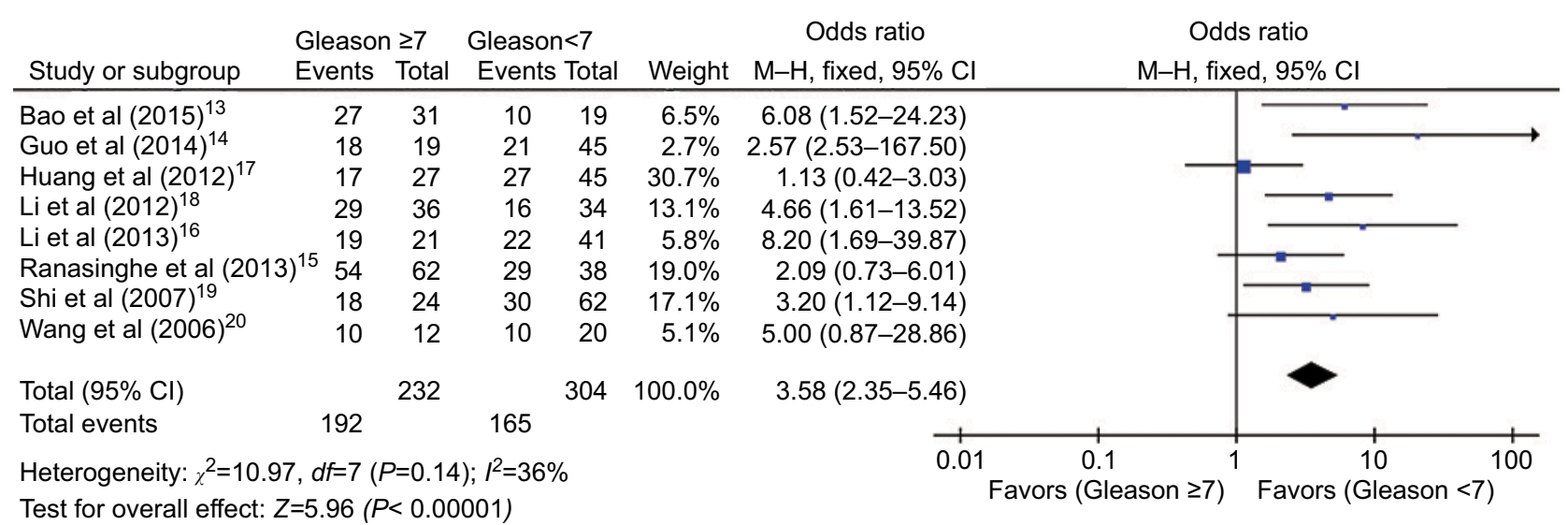

Figure 3 Forest plot for HIF-I $\alpha$ protein expression in different Gleason score of PCa.

Abbreviations: $\mathrm{HIF}-\mathrm{I} \alpha$, hypoxia-inducible factor-I $\alpha$; $\mathrm{PCa}$, prostate cancer.

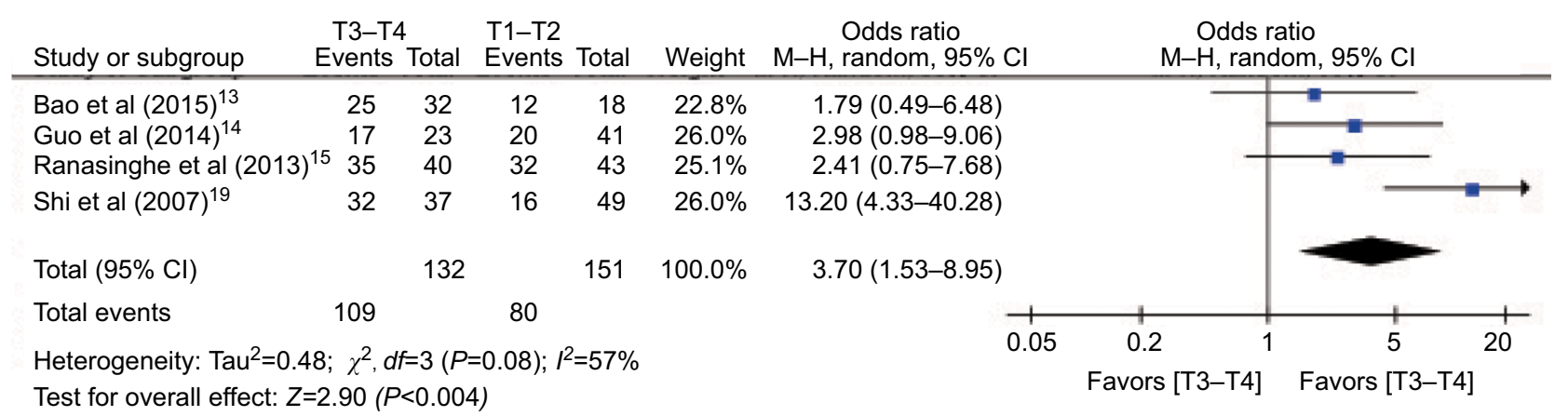

Figure 4 Forest plot for HIF-I $\alpha$ protein expression in different T stage of PCa.

Abbreviations: $\mathrm{HIF}-\mathrm{I} \alpha$, hypoxia-inducible factor- $\mathrm{I} \alpha$; PCa, prostate cancer.

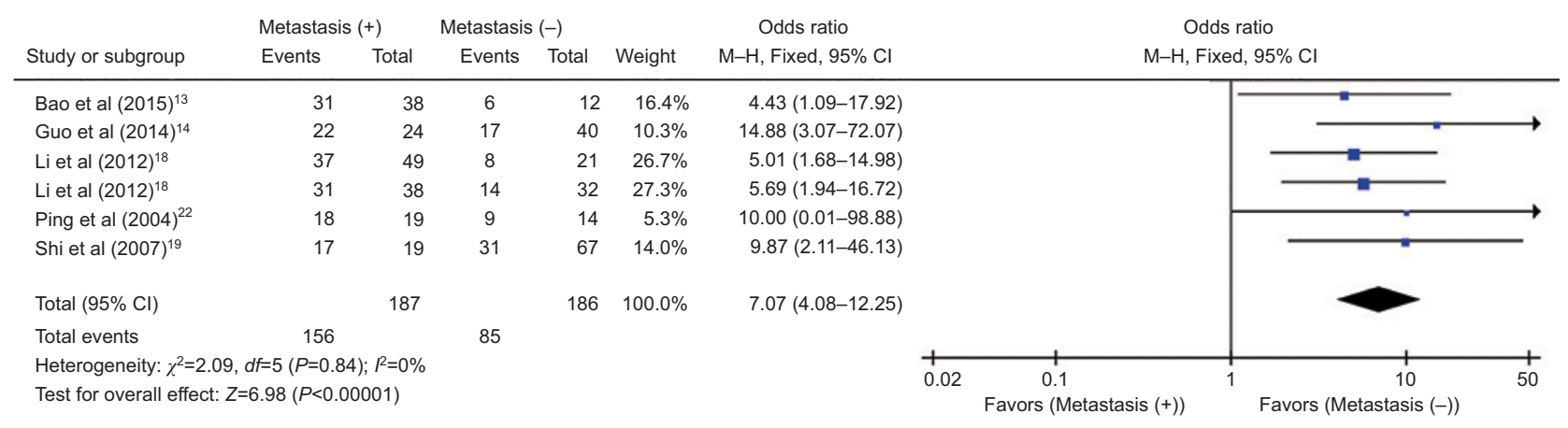

Figure 5 Forest plot for HIF-I $\alpha$ protein expresion in different metastasis status.

Abbreviations: $\mathrm{HIF}-\mathrm{I} \alpha$, hypoxia-inducible factor-I $\alpha$; $\mathrm{PCa}$, prostate cancer. 

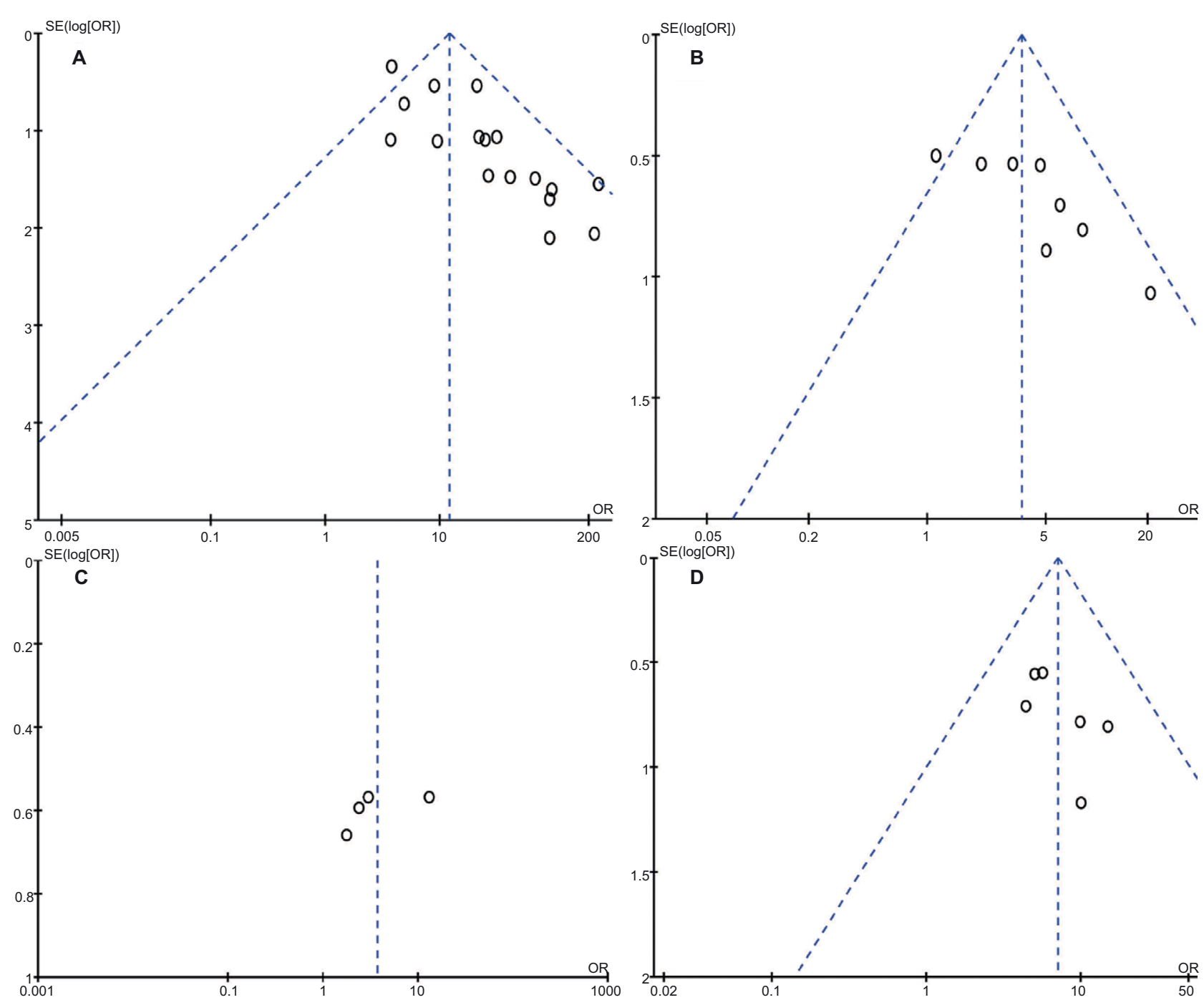

Figure 6 Funnel plots for publication bias.

Notes: (A) HIF-I $\alpha$ protein expression in PCa and nonmalignant prostate tissue; (B) HIF-I $\alpha$ protein expression in different Gleason score of PCa; (C) HIF-I $\alpha$ protein expression in different T stage of PCa; and (D) HIF-I $\alpha$ protein expression in different metastasis status.

Abbreviations: HIF-I $\alpha$, hypoxia-inducible factor-I $\alpha$; PCa, prostate cancer; OR, odds ratio.

the adjacent normal tissues. Transient or acute hypoxia occurs in tumors with inadequate blood perfusion, while chronic hypoxia occurs in tumors with limitation of oxygen diffusion. ${ }^{28}$ The ability of cells to adapt to hypoxia is dependent on a family of HIFs, which induce expression of $\sim 1.0 \%-1.5 \%$ specific target genes. ${ }^{29}$ The targets of HIF- 1 in the glycolytic pathway consist of glucose transporters 1 and 3 (GLUT1 and GLUT3) and enzymes such as hexokinase 2 (HK2) and lactate dehydrogenase A (LDHA), which are also direct targets of the oncogenic MYC transcription factor. ${ }^{30,31}$ In addition, HIF-1 $\alpha$ also induces the secretion of interleukin-6, vascular endothelial growth factor (VEGF), and connective tissue growth factor (CTGF) in cancer- associated fibroblasts (CAFs), which are involved in cancer progression by making contributions to invasion, metastasis, and angiogenesis. ${ }^{32,33}$ Recently, it has been addressed that HIF- $1 \alpha$ could mediate tumor progression through shifting metabolism toward glycolysis, induction of angiogenesis, regulation of apoptosis, induction of migration eventually making cancer cells to escape hostile hypoxic environments, and resist to therapeutics. ${ }^{34,35} \mathrm{~A}$ hallmark of the progression of PCa to advanced disease is the acquisition of androgenindependent growth. ${ }^{36} \mathrm{It}$ is well established that PCa under hypoxia often possessed aggressive tumor phenotypes, and even chemotherapy or radiotherapy resistance. ${ }^{37} \mathrm{An}$ effective therapy against $\mathrm{PCa}$ under hypoxia is desperately 
needed. Recent studies presented the inhibitory effects of tocotrienol and its redox-silent analog which could inhibit the survival of PC3 stem-like cells under hypoxia, primarily through the suppression of HIF-1 $\alpha$ signaling, and may subsequently establish the newly effective therapeutic approach for androgen-independent $\mathrm{PCa} .{ }^{38,39}$

Recent advances have explored a central role of HIF-1 $\alpha$ in $\mathrm{PCa}$ development and progression. The investigations that focused on the clinical correlation of HIF-1 $\alpha$ with PCa progression were relatively rare and inconclusive, which could be explained by the relatively small sample sizes. Meta-analysis is a useful tool to obtain a relatively precise estimation. As a result, association of HIF- $1 \alpha$ expression with PCa clinicopathological significance was explored in current meta-analysis to elucidate the role of HIF- $1 \alpha$ in PCa progression. In conclusion, the rate of HIF- $1 \alpha$ protein expression in PCa was significantly higher than in nonmalignant prostate tissues. The increased expression of HIF-1 $\alpha$ protein was significantly associated with clinicopathological significance for patients suffering from PCa.

\section{Limitations}

First, published studies written only in English or Chinese might not provide sufficient evidences which may subsequently result in certain publication bias. Additionally, studies without a consistent HIF-1 $\alpha$ cutoff value may influence the ultimate results. Meanwhile, the heterogeneity suggested that potential or undiscovered factors might be ignored. Despite limitations, a certain relationship of HIF-1 $\alpha$ expression with $\mathrm{PCa}$ clinicopathological significance has been explored in current meta-analysis.

\section{Conclusion}

The high expression of HIF-1 $\alpha$ protein was significantly associated with clinical diagnostic and clinicopathological significances for patients with PCa. Taken together, our findings have indicated that HIF-1 $\alpha$ expression was a potentially diagnostic biomarker of PCa and could potentially be applied for noninvasively monitoring progression of PCa patients in the future.

\section{Acknowledgments}

This meta-analysis was supported by grants from the Clinical Key Subjects Program of the Ministry of Public Health (Urology), the National Natural Science Foundation of China (81630019). The funders had no role in study design, data collection and analysis, decision to publish, or preparation of the manuscript.

\section{Disclosure}

The authors report no conflicts of interest in this work.

\section{References}

1. Siegel RL, Miller KD, Jemal A. Cancer statistics, 2017. CA Cancer J Clin. 2017;67(1):7-30.

2. Yap TA, Smith AD, Ferraldeschi R, Al-Lazikani B, Workman P, de Bono JS. Drug discovery in advanced prostate cancer: translating biology into therapy. Nat Rev Drug Discov. 2016;15(10):699-718.

3. Zhao R, Wang Y, Zhang M, et al. Screening of potential therapy targets for prostate cancer using integrated analysis of two gene expression profiles. Oncol Lett. 2017;14(5):5361-5369.

4. Schito L, Semenza GL. Hypoxia-inducible factors: master regulators of cancer progression. Trends Cancer. 2016;2(12):758-770.

5. Mak P, Li J, Samanta S, Mercurio AM. ER $\beta$ regulation of NF-kB activation in prostate cancer is mediated by HIF-1. Oncotarget. 2015;6(37): 40247-40254.

6. Xiao LJ, Chen YY, Lin P, et al. Hypoxia increases CX3CR1 expression via HIF-1 and NF- $\mathrm{KB}$ in androgen-independent prostate cancer cells. Int J Oncol. 2012;41(5):1827-1836.

7. Munafo MR, Flint J. Meta-analysis of genetic association studies. Trends Genet. 2004;20(9):439-444.

8. Higgins JP, Thompson SG. Quantifying heterogeneity in a meta-analysis. Stat Med. 2002;21(11):1539-1558.

9. DerSimonian R, Laird N. Meta-analysis in clinical trials. Control Clin Trials. 1986;7(3):177-188.

10. Mantel N, Haenszel W. Statistical aspects of the analysis of data from retrospective studies of disease. J Natl Cancer Inst. 1959;22(4):719-748.

11. Begg CB, Berlin JA. Publication bias and dissemination of clinical research. J Natl Cancer Inst. 1989;81(2):107-115.

12. Wu F, Ding S, Li X, et al. Elevated expression of HIF-l $\alpha$ in actively growing prostate tissues is associated with clinical features of benign prostatic hyperplasia. Oncotarget. 2016;7(11):12053-12062.

13. Bao XZ, Fan GM, Wu ZM, et al. Expression and significance of HIF-l $\alpha$ in prostate cancer. Mod Chin Dr. 2015;53(7):1-3.

14. Guo W, Chen MN, He XL, et al. Expression and clinical significance of HIF-1( VEGF and VEGFR-3 in prostate cancer. $J$ Contemp Urol Reproduct Oncol. 2014;6(4):231-234.

15. Ranasinghe WK, Xiao L, Kovac S, et al. The role of hypoxia-inducible factor $1 \alpha$ in determining the properties of castrate-resistant prostate cancers. PLoS One. 2013;8(1):e54251.

16. Li X, He CH, Xu CB, Li YP. Expressions and clinical significances of nuclear factor- $\mathrm{\kappa B}$ and hypoxia inducible factor- $1 \alpha$ in prostate cancer. J Chongqing Med Univ. 2013;38(8):872-875.

17. Huang $\mathrm{H}, \mathrm{Lu} Z \mathrm{ZQ}, \mathrm{Du} \mathrm{T}$, et al. The expression and correlation studies about carbon anhydrase IX (CA-IX) and hypoxia-inducible factor-1 prostate cancer. Chin J Endourol. 2012;6(5):405-409.

18. Li W, Zhang HD, Li ZQ, Yu ZG, Niu XD, Li ZQ. Expression of VEGF and HIF- $1 \alpha$ in prostate adenocarcinoma and their significance. Med $J$ Chin Peoples Liberation Army. 2012;24(5):11-13.

19. Shi HQ, Zhai XL, Liu QW. Expression and clinical significance of HIF-1 $\alpha$ in prostate cancer. J Pract Oncol. 2007;3(89):265-267.

20. Wang L, Chen ZJ, Wang QT, et al. Expression of hypoxia-inducible factor 1 alpha and vascular endothelial growth factor in prostate cancer and its significance. Zhonghua Nan Ke Xue. 2006;12(1):57-59.

21. Lekas A, Lazaris AC, Deliveliotis $C$, et al. The expression of hypoxiainducible factor-1 alpha (HIF-1alpha) and angiogenesis markers in hyperplastic and malignant prostate tissue. Anticancer Res. 2006;26(4B): 2989-2993.

22. Ping H, Chen XC, Wang H, Chen CH, Zeng FC, Lu GC. Expression and significance of HIF-l $\alpha$ in prostate cancer. Chin JUrol. 2004;25(2):88-90.

23. Zhong H, Semenza GL, Simons JW, De Marzo AM. Up-regulation of hypoxia-inducible factor 1alpha is an early event in prostate carcinogenesis. Cancer Detect Prev. 2004;28(2):88-93. 
24. Du Z, Fujiyama C, Chen Y, Masaki Z. Expression of hypoxia-inducible factor 1alpha in human normal, benign, and malignant prostate tissue. Chin Med J (Engl). 2003;116(12):1936-1939.

25. Zhong H, De Marzo AM, Laughner E, et al. Overexpression of hypoxiainducible factor 1 alpha in common human cancers and their metastases. Cancer Res. 1999;59(22):5830-5835.

26. Teitelbaum AH, Bui CN, Spalding JR. Treatment patterns of castrationresistant prostate cancer: a retrospective claims database analysis. J Clin Oncol. 2012;30(34_suppl):198.

27. Roviello G, Corona SP, Bonetta A, Cappelletti MR, Generali D. Circulating tumor cells correlate with patterns of recurrence in patients with hormone-sensitive prostate cancer. Onco Targets Ther. 2017;10:3811-3815.

28. Vaupel P, Mayer A. Hypoxia in tumors: pathogenesis-related classification, characterization of hypoxia subtypes, and associated biological and clinical implications. Adv Exp Med Biol. 2014;812(812):19-24.

29. Semenza GL. Oxygen sensing, hypoxia-inducible factors and disease pathophysiology. Annu Rev Pathol. 2014;9(1):47-71.

30. Christofk HR, Vander Heiden MG, Harris MH, et al. The M2 splice isoform of pyruvate kinase is important for cancer metabolism and tumor growth. Nature. 2008;452(7184):230-233.

31. Dang CV, Kim JW, Gao P, Yustein J. The interplay between MYC and HIF in cancer. Nat Rev Cancer. 2008;8(1):51-56.
32. De Francesco EM, Lappano R, Santolla MF, Marsico S, Caruso A, Maggiolini M. HIF-1a/GPER signaling mediates the expression of VEGF induced by hypoxia in breast cancer associated fibroblasts (CAFs). Breast Cancer Res. 2013;15(4):R64.

33. Ren J, Guo H, Wu H, et al. GPER in CAFs regulates hypoxia-driven breast cancer invasion in a CTGF-dependent manner. Oncol Rep. 2015;33(4): 1929-1937.

34. Karakashev SV, Reginato MJ. Progress toward overcoming hypoxiainduced resistance to solid tumor therapy. Cancer Manag Res. 2015;7:253-264.

35. Luo D, Wang Z, Wu J, Jiang C, Wu J. The role of hypoxia inducible factor-1 in hepatocellular carcinoma. Biomed Res Int. 2014;2014(3-4): 409272.

36. Zhang W, Meng Y, Liu N, Wen XF, Yang T. Insights into chemoresistance of prostate cancer. Int J Biol Sci. 2015;11(10):1160-1170.

37. Harris AL. Hypoxia - a key regulatory factor in tumour growth. Nat Rev Cancer. 2002;2(1):38-47.

38. Kaneko S, Sato C, Shiozawa N, et al. Suppressive effect of deltatocotrienol on hypoxia adaptation of prostate cancer stem-like cells. Anticancer Res. 2018;38(3):1391-1399.

39. Shiozawa N, Sugahara R, Namiki K, et al. Inhibitory effect of a redoxsilent analogue of tocotrienol on hypoxia adaptation in prostate cancer cells. Anticancer Drugs. 2017;28(3):289-297.
Cancer Management and Research

\section{Publish your work in this journal}

Cancer Management and Research is an international, peer-reviewed open access journal focusing on cancer research and the optimal use of preventative and integrated treatment interventions to achieve improved outcomes, enhanced survival and quality of life for the cancer patient. The manuscript management system is completely online and includes
Dovepress

a very quick and fair peer-review system, which is all easy to use. Visit http://www.dovepress.com/testimonials.php to read real quotes from published authors. 